\title{
Potential use of flow cytometry in toxicity studies with microalgae
}

Dolores Franqueira, Miguel Orosa, Enrique Torres, Concepción Herrero, Ángeles Cid¹

Science of The Total Environment, Volume 247, Issues 2-3, 20 March 2000, Pages

119-126

Available online 21 March 2000

DOI: 10.1016/S0048-9697(99)00483-0

\begin{abstract}
Cytotoxic effects of aquatic pollutants on microalgae are very heterogeneous, and they are influenced by environmental conditions and the test species. Stress produced by copper or paraquat addition to the culture medium of two microalgae was analysed by flow cytometry. Parameters assayed were: cell volume, chlorophyll a fluorescence and cell viability. The variety of results obtained in the present study reveals that flow cytometry is a useful tool in the toxicity tests with microalgae, both marine and freshwater species, and for different kind of pollutants.
\end{abstract}

\section{Keywords}

Microalgae; Aquatic toxicity test; Copper; Paraquat; Flow cytometry

\section{Introduction}

All types of pollutant provoke changes in the structure of ecosystems, affecting biotic communities. Microorganisms are the lowest biological level affected by the discharges of pollutants in an ecosystem, as they are directly in contact with the medium, only separated by a membrane and/or cell wall. Microalgae have already been used as biological indicators to assay pollutant toxicity in marine or freshwater environments (Hörnström, 1990).

It has been confirmed that inhibition of growth and photosynthesis, as well as other variables closely related to photosynthesis, such as ATP formation, radioactive carbon assimilation, oxygen evolution and algal fluorescence induction phenomena, reflect the toxic effects of pollutants on microalgae (Paau et al., 1978, Wong et al., 1980, Sicko-Goad, 1982, Ibrahim, 1990, Blaise, 1993, Cid et al., 1995 and Saenz et al., 1997). Nevertheless, other relevant endpoints are less known because experimental difficulties, especially under in vivo conditions. Flow cytometry (FCM) has been applied in the study of the aquatic environment since the 1980s (Yentsch and Pomponi, 1986); this technique has achieved extensive use in the study of microalgae and has been introduced as an alternative to the more traditional techniques of

\footnotetext{
${ }^{1}$ Laboratorio de Microbioloxía, Facultade de Ciencias, Universidade da Coruña, Campus da Zapateira s/n, 15071 A Coruña, Spain
} 
analysing cells in culture and from natural populations (Yentsch and Horan, 1989, Reiriz et al., 1994, Abalde et al., 1995 and Cid et al., 1996).

In the present study, some measurements obtained by flow cytometry, such as cellular volume, chlorophyll afluorescence and cellular viability, were employed to assess the toxic action of two different pollutants on microalgae, analysing the effect of copper on the marine diatom Phaeodactylum tricornutum and the effect of the herbicide paraquat on the freshwater microalga Chlamydomonas eugametos.

\section{Material and methods}

\subsection{Microalgal cultures}

The marine microalga, Phaeodactylum tricornutum Bohlin (Bacillariophyceae) was cultured in raw seawater as described previously ( Cid et al., 1995), salinity 35\%, and initial pH 8.4. Initial cell density was $0.24 \times 10^{6}$ cells $\mathrm{ml}^{-1}$. Copper concentration assayed was $1 \mathrm{mg} \mathrm{Cu} \mathrm{l-1}$, added as copper chloride; control cultures without copper were also included. Cultures were illuminated with $140 \mu \mathrm{mol}$ photon $\mathrm{m}^{-2} \mathrm{~s}^{-1}$.

The freshwater microalga, Chlamydomonas eugametos Moewus (Chlamydomonadaceae) was cultured in Bristol medium as described before ( Franqueira et al., 1999), supplemented with the herbicide paraquat at a final concentration of $0.6 \mu \mathrm{M}$. Initial cell density was $0.10 \times 10^{6}$ cells $^{-1}$. Cultures without paraquat were included as control cultures. Cultures were illuminated with $68.25 \mu \mathrm{mol}$ photon $\mathrm{m}^{-2} \mathrm{~s}^{-1}$.

All experiments were carried out in triplicate. Cultures were maintained at $18 \pm 1^{\circ} \mathrm{C}$, with a lightdark cycle of $12 \mathrm{~h}: 12 \mathrm{~h}$, during $96 \mathrm{~h}$ as has already been indicated for toxicity assays with microalgae (Walsh and Merril, 1984).

\subsection{Growth measurement}

Growth of the microalgal cultures was determined daily by counting culture aliquots in a Malassez or Neubauer haemocytometer. Growth rate $(\mu)$, expressed in day-1 $\left(d^{-1}\right)$ was calculated by the usual formula:

$\mu=\left(\ln N_{t}-\ln N_{0}\right) /\left(t-t_{0}\right)$

where $N$ is cellular density at time $t$ after pollutant exposure and time is expressed in days.

\subsection{Flow cytometry analysis}

Stress produced by the heavy metal or the pesticide addition was analysed by flow cytometry, using cell volume, chlorophyll a fluorescence and cell viability as toxicity parameters.

Aliquots of microalgal cultures were collected after 24 and $96 \mathrm{~h}$ of treatment; these aliquots were centrifuged and washed twice, and resuspended in buffered saline solution to be analysed in a FACScan flow cytometer (Becton Dickinson Instruments) equipped with an argon-ion laser 
(blue light, $488 \mathrm{~nm}$ ). Chlorophyll a red fluorescence histograms were used to set gating levels, excluding particles without red fluorescence, which are obviously non-algal particles.

The fluorescence of cells stained with propidium iodide $(\mathrm{PI})$ was measured to study the cell viability. $\mathrm{PI}$ is a fluorescent dye that intercalates with double-stranded nucleic acids to produce red fluorescence when excited by blue light. It is unable to pass through intact cell membranes; however, when the cell dies the integrity of the cell membrane fails, and $\mathrm{PI}$ is able to enter and stain the nucleic acids (Ormerod, 1990). In this way, PI can be used to discriminate between live non-fluorescent cells and non-viable fluorescent cells.

\subsubsection{Staining protocol}

Aliquots of cells were washed as indicated before and stained with $\mathrm{PI}$ at a final concentration of $60 \mu \mathrm{M}$, during an incubation period of $20 \mathrm{~min}$, at room temperature and darkness conditions. The cell viability of the cultures is expressed as the percentage of viable cells vs. the total amount of cells analysed by flow cytometry.

Since the forward light scatter signal (FSC) can be correlated with the size of the cell (Shapiro, 1995), aliquots of microalgal cultures stained with PI, were analysed to study the possible changes in cell volume. Only viable cells were analysed.

For each cytometric parameter investigated, at least $10^{4}$ gated cells were analysed per culture and fluorescence measurements were expressed in a logarithmic scale. Data collection was performed using the list mode and statistically analysed by the instrument software (LYSIS II Program; Becton Dickinson Instruments).

\section{Results}

\subsection{Effect of copper on Phaeodactylum tricornutum}

The concentration of copper assayed $\left(1 \mathrm{mg} \mathrm{l}^{-1}\right)$ inhibited the growth of the marine diatom $P$. tricornutum ( Fig. 1), with a growth rate close to $0\left(0.001\right.$ days $\left.^{-1}\right)$, while in control cultures, without copper, growth rate was 1.16 days $^{-1}$. This copper concentration also provokes changes in cell viability, cellular volume and chlorophyll afluorescence. Cell density after $96 \mathrm{~h}$ of copper exposure was $0.23 \times 10^{6}$ cells $\mathrm{ml}^{-1}\left(S . D .=0.03 \times 10^{6}\right)$, while in control cultures the density was 1.49 $\times 10^{6}$ cells $\mathrm{ml}^{-1}\left(\right.$ S.D. $\left.=0.12 \times 10^{6}\right)($ Fig. 1$)$. 


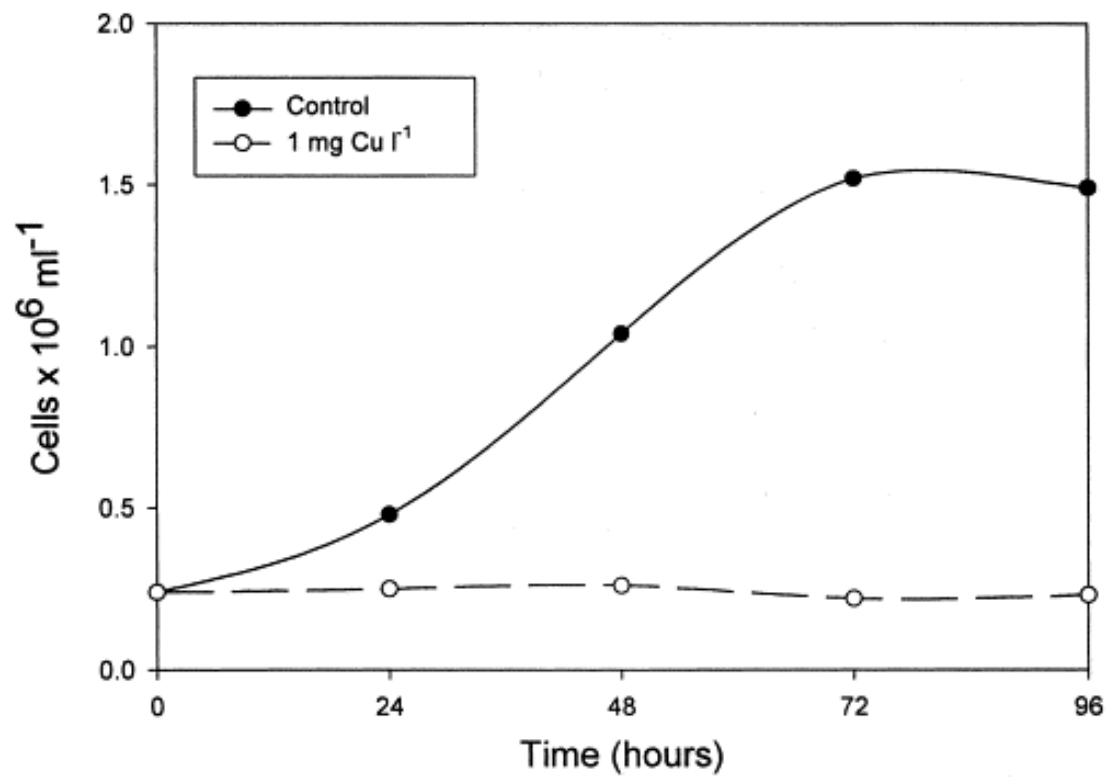

Fig. 1.

Growth curves of $P$. tricornutum cultures. Results are the means of three replicates.

In control cultures of $P$. tricornutum, cell viability remains constant near to $100 \%$ during the $96 \mathrm{~h}$ of the experiment; however, in cultures with copper the cell viability decrease over this time period ( Table 1). The copper concentration assayed $\left(1 \mathrm{mg} \mathrm{l}^{-1}\right)$ reduced the cell viability of $P$. tricornutum to $8 \%$ after $96 \mathrm{~h}$ of treatment.

Table 1.

Percentage of viable cells (non-stained with propidium iodide) of $P$. tricornutum and $C$. eugametos after 24 and $96 \mathrm{~h}$ of culture, with respect to the total amount of analysed cells by flow cytometry

\begin{tabular}{|c|c|c|c|c|c|}
\hline & \multicolumn{2}{|c|}{ P. tricornutum } & & \multicolumn{2}{|c|}{ C. eugametos } \\
\hline & $24 \mathrm{~h}$ & $96 \mathrm{~h}$ & & $24 \mathrm{~h}$ & $96 \mathrm{~h}$ \\
\hline Control & $100 \%$ & $96 \%$ & Control & $100 \%$ & $99 \%$ \\
\hline+ Copper & $97 \%$ & $8 \%$ & +paraquat & $97 \%$ & $38 \%$ \\
\hline
\end{tabular}

Copper provokes changes in the FSC signal, related to changes of cell volume, of $P$. tricornutum cells with respect to the volume seen in control cultures ( Fig. 2). Copper provokes an increase of the cell volume after $96 \mathrm{~h}$ of treatment, while this difference is not observable after $24 \mathrm{~h}$ ( Fig. 2). The treatment of the data obtained showed an increase of $49 \%$ in the FSC signal of cells exposed during $96 \mathrm{~h}$ to copper with respect to the control ones.
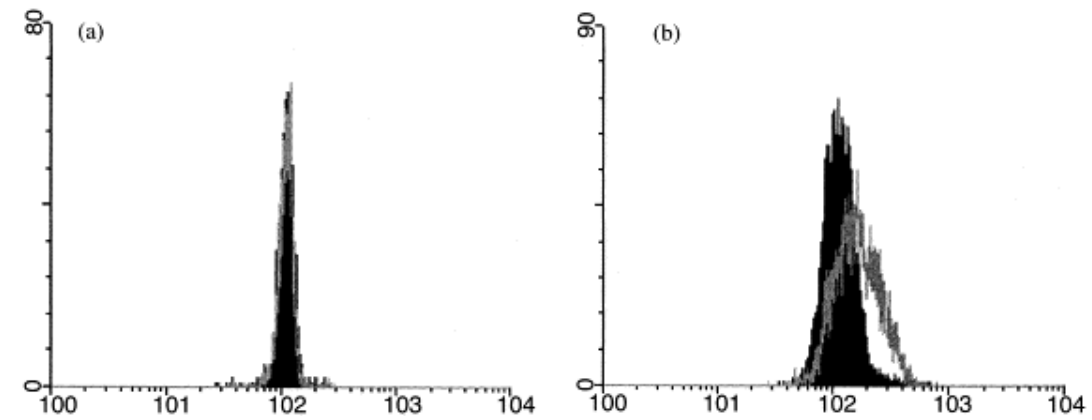

Fig. 2. 
Overlay of FSC signal (related with cell volume) histograms showing the profiles of a $P$. tricornutum control culture sample (solid histogram) and a sample of a culture with a copper concentration of $1 \mathrm{mg} \mathrm{l}^{-1}$, after 24 and $96 \mathrm{~h}$ of culture ( $\mathrm{a}$ and $\mathrm{b}$, respectively).

Chlorophyll a fluorescence of $P$. tricornutum cells was also affected by the copper concentration assayed. After $24 \mathrm{~h}$ of treatment, this chlorophyll a fluorescence detected by flow cytometry increased, but this increase is more important after $96 \mathrm{~h}$ of exposure to copper ( Fig. 3).
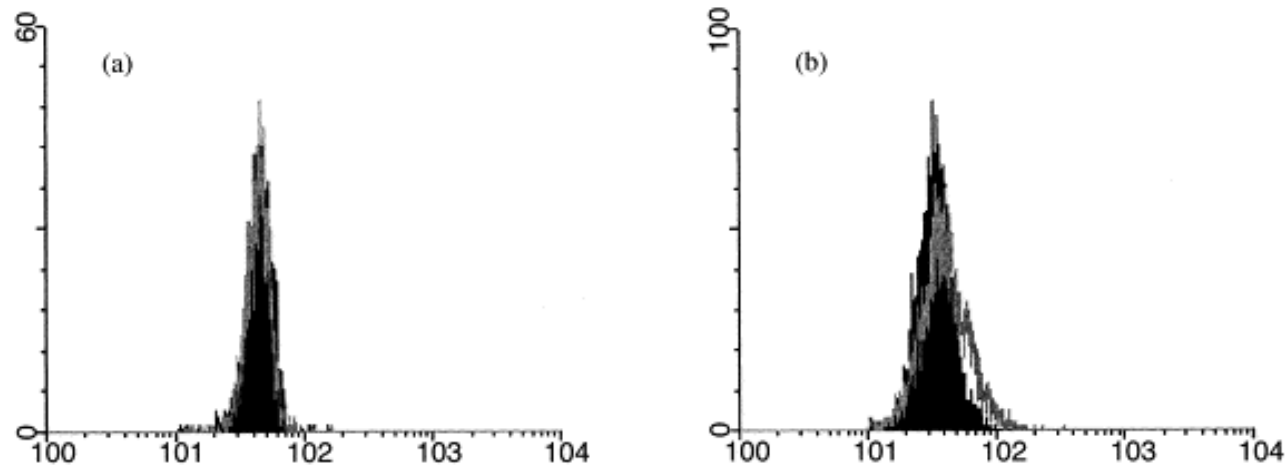

Fig. 3.

Overlay of chlorophyll a fluorescence histograms showing the profiles of a $P$. tricornutum control culture sample (solid histogram) and a sample of a culture with a copper concentration of $1 \mathrm{mg} \mathrm{l}^{-1}$, after 24 and $96 \mathrm{~h}$ of culture ( $\mathrm{a}$ and $\mathrm{b}$, respectively).

\subsection{Effect of paraquat on Chlamydomonas eugametos}

Growth of $C$. eugametos cultures were totally inhibited by the paraquat concentration assayed and the cell density of paraquat exposed cultures decreased over the $96 \mathrm{~h}$ of the assay ( Fig. 4). After $96 \mathrm{~h}$ of culture, the cell density of control cultures was $0.85 \times 10^{6}$ cells $\mathrm{ml}^{-1}\left(\right.$ S.D. $\left.=0.01 \times 10^{6}\right)$, while cell density of paraquat exposed cultures was $0.05 \times 10^{6}$ cells $\mathrm{ml}^{-1}\left(\right.$ S.D. $\left.=0.01 \times 10^{6}\right)$ ( Fig. 4 ).

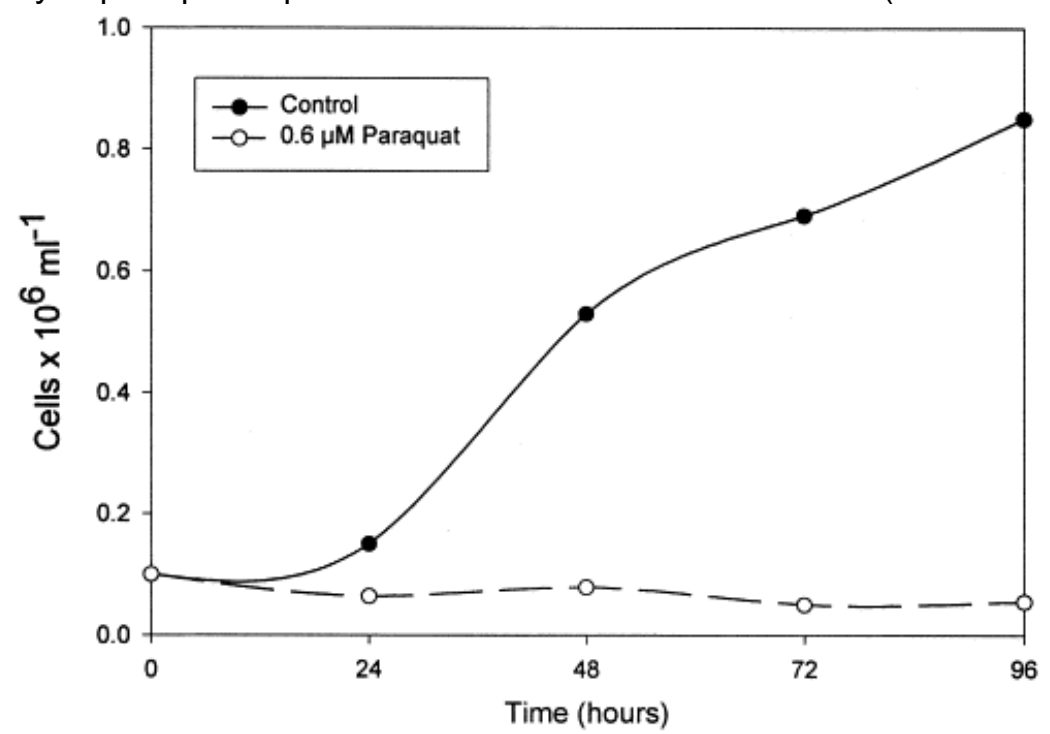

Fig. 4.

Growth curves of $C$. eugametos cultures. Results are the means of three replicates. 
C. eugametos cultures with paraquat showed an important decrease in the percentage of viable cells after $96 \mathrm{~h}$ of exposure to the herbicide (38\%) ( Table 1). The cell viability of control cultures, without paraquat, remains constant near to the $100 \%$ over the $96 \mathrm{~h}$ of the experiment. The concentration assayed of the herbicide paraquat also provokes changes in the cellular volume of $C$. eugametos with respect to the volume shown in control cultures ( Fig. 5). After 24 $\mathrm{h}$ of treatment, the cell volume of this microalga showed alterations, but most cells of paraquat cultures showed an FSC signal similar to the control cells after $24 \mathrm{~h}$. However, after $96 \mathrm{~h}$ of paraquat exposure, this FSC signal is more heterogeneous, having practically the same mode of distribution for control and paraquat cultures ( $\underline{\text { Fig. } 5}$ ).
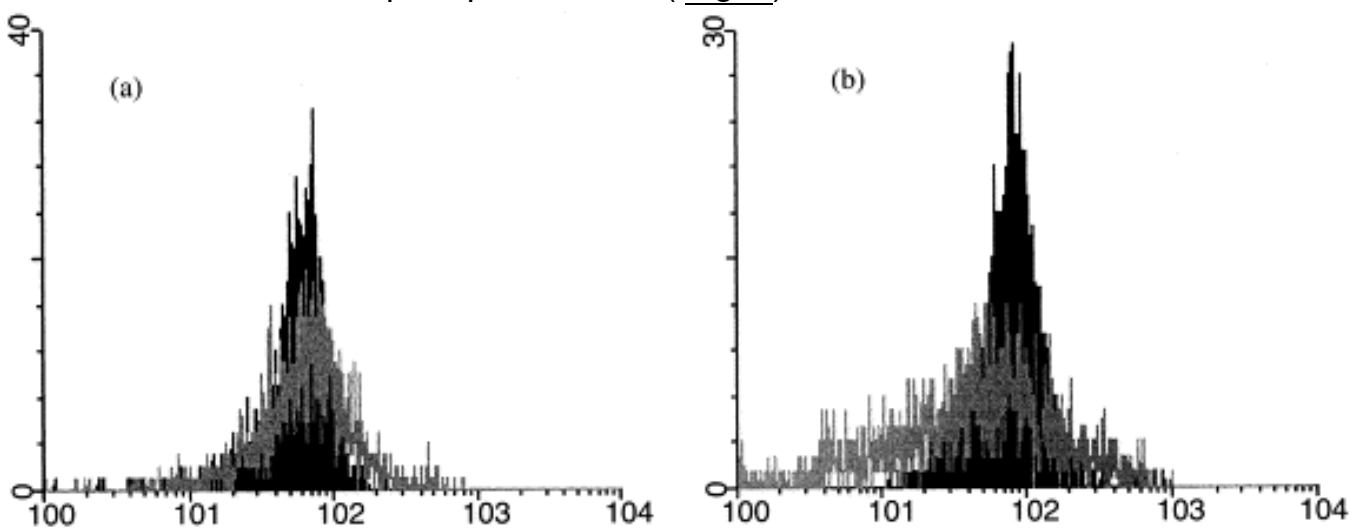

Fig. 5.

Overlay of FSC signal (related with cell volume) histograms showing the profiles of a $C$. eugametos control culture sample (solid histogram) and a sample of a culture with a paraquat concentration of $0.60 \mu \mathrm{M}$, after 24 and $96 \mathrm{~h}$ of culture ( $\mathrm{a}$ and $\mathrm{b}$, respectively).

Paraquat concentration assayed modified the chlorophyll a fluorescence ( Fig. 6). After $24 \mathrm{~h}$ of treatment the chlorophyll a fluorescence seems to be lower than the control cells, but only slightly lower; however, after $96 \mathrm{~h}$ the chlorophyll a fluorescence signal decreased strongly in comparison to the signal provided by control cultures cells ( $\underline{\text { Fig. } 6 \text { ). }}$.
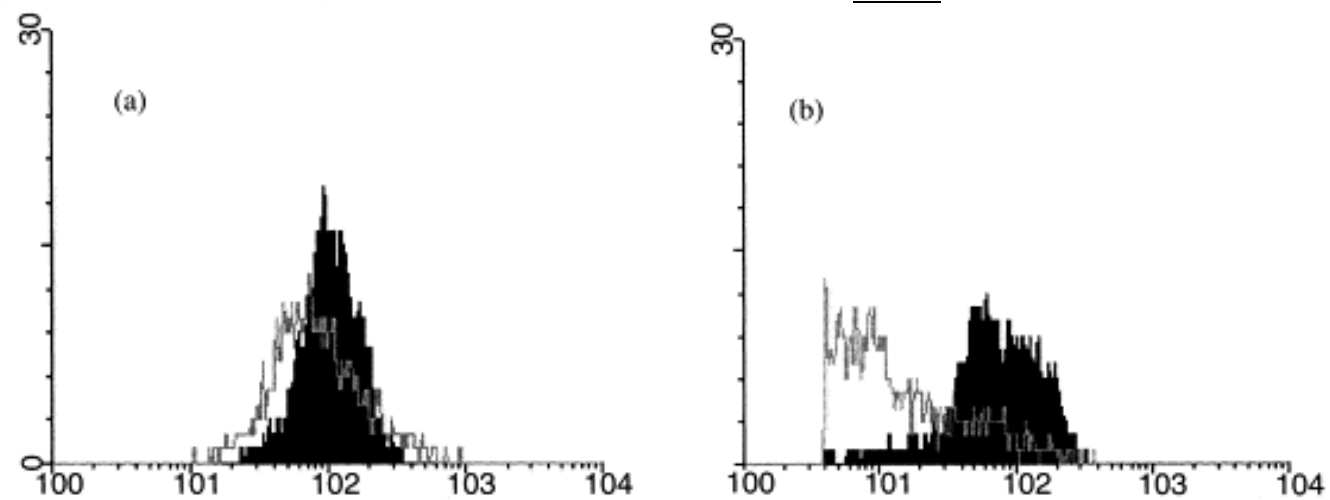

Fig. 6.

Overlay of chlorophyll a fluorescence histograms showing the profiles of $C$. eugametos control culture sample (solid histogram) and a sample of a culture with a paraquat concentration of $0.60 \mu \mathrm{M}$, after 24 and $96 \mathrm{~h}$ of culture ( $\mathrm{a}$ and $\mathrm{b}$, respectively).

\section{Discussion}


Cytotoxic effects of aquatic pollutants on microalgae are very heterogeneous, and they are influenced by the environmental conditions and the test species. The assayed copper and paraquat concentrations ( $1 \mathrm{mg} \mathrm{l} \mathrm{I}^{-1}$ and $0.60 \mu \mathrm{M}$, respectively) provoked the total inhibition of growth (Fig. 1 and Fig. 4), this parameter being one of the most commonly used in toxicity tests. Copper is an essential micronutrient for growth, metabolism, and enzyme activities of algae, cyanobacteria, and other organisms; however, it is also a proven inhibitor of algal growth at high concentrations (Lustigman, 1986, Stauber and Florence, 1987 and Abalde et al., 1995). Microalgal cells would be able to tolerate the presence of certain herbicide concentrations without significant effects on growth (Rabinowitch et al., 1983 and Bray et al., 1993); however, their defense mechanisms would be overcome at higher exposure levels (Kirtikara and Talbot, 1996).

Flow cytometry allows the rapid analysis of structural characteristics, as the cell volume, of cells without staining. Both pollutants assayed, copper and paraquat, provoke changes in the cellular volume of $P$. tricornutum and $C$. eugametos with respect to the volume shown in control cultures ( Fig. 2 and Fig. 5). P. tricornutum cells showed an increase in the FSC signal when exposed to the copper concentration assayed (Fig. 2). Several authors, using optical or electron microscopy, have observed an increase in the cell volume of different microalgal species in response to toxic levels of heavy metals (Fisher et al., 1981, Stauber and Florence, 1987 and Bolaños et al., 1992), and also using flow cytometry ( Abalde et al., 1995). Heavy metals change cell membrane permeability to small cations ( Overnell, 1975), and the increase in cell volume is probably due to the increase of the permeability of cell membrane to $\mathrm{Na}^{+}$( Riisgård et al., 1980).

Bray et al. (1993) also observed an increase of the cellular volume of Chlamydomonas reinhardtii exposed to paraquat. Variations observed in the FSC signal detected by FCM in the $C$. eugametos cultures treated with $0.60 \mu \mathrm{M}$ paraquat ( Fig. 5) could be related to palmeloid colony formation, since several factors can induce the formation of these structures in the genus Chlamydomonas ( Nakamura et al., 1976 and Olsen et al., 1983). This palmeloid structure appears probably due to the incapacity to finish cell division, as well as failures of regulation of cellular volume as a consequence of the high levels of oxidative radicals formed. However, an important proportion of the analysed cells presented a lower FSC signal also ( Fig. 5), and may be due to the inhibition of growth in these cultures ( Fig. 4).

Chlorophyll a fluorescence is determined by flow cytometry and it is a good indicator of the physiological state of this kind of photoautotrophic cells ( Cid et al., 1995). Measurement of the fluorescence of chlorophylla in intact algal cells provides information on the absorption, distribution and utilisation of energy in photosynthesis ( $\underline{\text { Hawkins and Griffiths, }}$ 1982 and Phinney and Cucci, 1989). Algal fluorescence induction phenomena were used to study phytotoxicity ( Sicko-Goad, 1982 and Murthy et al., 1989). Chlorophyll afluorescence monitored by the single-laser based flow cytometer is the maximum fluorescence when the

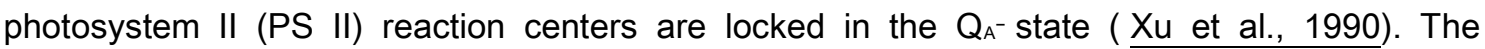
inhibition of the electron flow in the PS II reaction center in the donor side induces a decrease in 
the chlorophyll afluorescence ( Overnell, 1975, Butler, 1977 and Samson and Papovic, 1988) as occur in C. eugametos cells affected by the paraquat concentration assayed ( Fig. 6). However, when the inhibition of this electron flow is produced in the acceptor side of the PS II, an increase in the chlorophyll a fluorescence is observed (Overnell, 1975, Butler, 1977 and Samson and Papovic, 1988), as can be observed in P. tricornutum cultures with copper ( Fig. 3). According to other authors copper's inhibitory effect on PS II activity is located on its oxidising side (Samson and Papovic, 1988), probably because copper inactivates some PS II reaction centers.

The variety of results obtained in the present study reveal that flow cytometry is a useful tool in toxicity tests with microalgae, both marine and freshwater species, and for different kinds of pollutants.

\section{Acknowledgements}

This work was supported by a research project from Consellería da Presidencia, Xunta de Galicia (Spain) (ref. XUGA10307A98). D. Franqueira and M. Orosa hold fellowships from the Plan Nacional F.P.U., Ministerio de Educación y Cultura (Madrid, Spain) and Consellería da Presidencia, Xunta de Galicia (Spain), respectively.

\section{References}

J. Abalde, A. Cid, S. Reiriz, E. Torres, C. Herrero

Response of the marine microalga Dunaliella tertiolecta (Chlorophyceae) to copper toxicity in short time experiments

Bull Environ Contam Toxicol, 54 (1995), pp. 317-324

\section{C.R. Blaise}

Practical laboratory applications with micro-algae for hazard assessment of aquatic contaminants

M. Richardson (Ed.), Ecotoxicology monitoring, Weinheim (1993), pp. 83-107

L. Bolaños, M. García-González, P. Mateo, I. Bonilla

Differential toxicological response to cadmium in Anabaena strain PCC 7119 grown with NO3- or NH4+ as nitrogen source

J Plant Physiol, 140 (1992), pp. 345-349

D.F. Bray, J.R. Bagu, K. Nakamura

Ultrastructure of Chlamydomonas reinhardtii following exposure to paraquat: comparison of wild type and a paraquat-resistant mutant

Can J Bot, 71 (1993), pp. 174-182

W.L. Butler

Chlorophyll fluorescence as a probe for electron transfer and energy transfer 
A. Trebst, M. Avron (Eds.), Encyclopedia of plant physiology. New Series, 5, Springer Verlag, Berlin (1977), pp. 149-167

A. Cid, C. Herrero, E. Torres, J. Abalde

Copper toxicity on the marine microalga Phaeodactylum tricornutum: effects on photosynthesis and related parameters

Aquat Toxicol, 31 (1995), pp. 165-174

A. Cid, P. Fidalgo, C. Herrero, J. Abalde

Toxic action of copper on the membrane system of a marine diatom measured by flow cytometry

Cytometry, 25 (1996), pp. 32-36

N.S. Fisher, G.J. Jones, D.M. Nelson

Effects of copper and zinc on growth, morphology and metabolism of Asterionella japonica (Cleve)

J Exp Mar Biol Ecol, 51 (1981), pp. 37-56

D. Franqueira, A. Cid, E. Torres, M. Orosa, C. Herrero

A comparison of the relative sensitivity of structural and functional cellular responses in the alga Chlamydomonas eugametos exposed to the herbicide paraquat

Arch Environ Contam Toxicol, 36 (1999), pp. 264-269

P.R. Hawkins, D.J. Griffiths

Cupric ion tolerance in four species of marine phytoplankton

Bot Mar, 25 (1982), pp. 31-33

E. Hörnström

Toxicity test with algae - a discussion on the batch method

Ecotoxicol Environ Safety, 20 (1990), pp. 343-353

E.A. Ibrahim

The influence of the herbicide paraquat 'gramoxon' on growth and metabolic activity of three chlorophytes Water Air Soil Pollut, 51 (1990), pp. 89-93

K. Kirtikara, D. Talbot

Alteration in protein accumulation, gene expression and ascorbate-glutathione pathway in tomato (Lycopersicon esculentum) under paraquat and ozone stress

J Plant Physiol, 148 (1996), pp. 752-760

B.K. Lustigman

Enhancement of pigment concentrations in Dunaliella tertiolecta as a result of copper toxicity

Bull Environ Contam Toxicol, 37 (1986), pp. 710-713

S.D.S. Murthy, S.C. Sabat, P. Mohanty 
Mercury-induced inhibition of photosystem II activity and changes in the emission of fluorescence from phycobilisomes in intact cells of the cyanobacterium, Spirulina platensis

Plant Cell Physiol, 30 (1989), pp. 1153-1157

K. Nakamura, M. Sakon, M.K. Hatanaka

Chemical factors affecting palmeloid-forming activity of chloroplatinic acid on Chlamydomonas eugametos Physiol Plant, 36 (1976), pp. 293-296

Y. Olsen, G. Knutsen, T. Lien

Characteristics of phosphorus limitation in Chlamydomonas reinhardtii (Chlorophyceae) and its palmelloids J Phycol, 19 (1983), pp. 313-319

M.G. Ormerod

Analysis of DNA. General methods

M.G. Ormerod (Ed.), Flow cytometry. A practical approach, Oxford University Press, Oxford (1990), pp. 69-87

\section{J. Overnell}

The effects of heavy metals on photosynthesis and loss of cell potassium in two species of marine algae, Dunaliella tertiolecta and Phaeodactylum tricornutum

Mar Biol, 29 (1975), pp. 99-103

A.S. Paau, J. Oro, J.R. Cowles

Application of flow microfluorometry to the study of algal cells and isolated chloroplasts

J Exp Bot, 29 (1978), pp. 1011-1020

D.A. Phinney, T.L. Cucci

Flow cytometry and phytoplankton

Cytometry, 10 (1989), pp. 511-521

H.D. Rabinowitch, D.A. Clare, J.D. Crapo, I. Fridovitch

Positive correlation between superoxide dismutase and resistance to paraquat toxicity in the green alga Chlorella sorokiniana

Arch Biochem Biophys, 225 (1983), pp. 640-648

S. Reiriz, A. Cid, E. Torres, J. Abalde, C. Herrero

Different responses of the marine diatom Phaeodactylum tricornutum to copper toxicity

Microbiol SEM, 10 (1994), pp. 263-272

H.U. Riisgård, K.N. Nielsen, B. Sogaard-Jensen

Further studies on volume regulation and effects of copper in relation to $\mathrm{pH}$ and EDTA in the naked marine flagellate Dunaliella marina

Mar Biol, 56 (1980), pp. 267-276 
M.E. Saenz, J.L. Alberdi, W.D. Di Marzio, J. Accorinti, M.C. Tortorelli

Paraquat toxicity to different green algae

Bull Environ Contam Toxicol, 58 (1997), pp. 922-928

G. Samson, R. Papovic

Use of algal fluorescence for determination of phytotoxicity of heavy metals and pesticides as environmental pollutants

Ecotoxicol Environ Safety, 16 (1988), pp. 272-278

H.M. Shapiro

Practical flow cytometry. 3rd ed, Willey-Lyss Inc, New York (1995), p. 542

L. Sicko-Goad

A morphometric analysis of algae response to low dose, short-term heavy metal exposure

Protoplasma, 110 (1982), pp. 75-86

J.L. Stauber, T.M. Florence

Mechanism of toxicity of ionic copper and copper complexes to algae

Mar Biol, 511 (1987), pp. 511-519

G.E. Walsh, R.G. Merril

Algal bioassays of industrial and energy process effluents

L.E. Shubert (Ed.), Algae as ecological indicators, Academic Press, London (1984), pp. 329-360

P.T.S. Wong, C.I. Mayfield, Y.K. Chau

Cadmium toxicity to phytoplankton and microorganisms

J.O. Nriagu (Ed.), Cadmium in the environment. Part I, John Wiley \& Sons, Inc, New York (1980)

C. Xu, J. Auger, Govindjee

Chlorophyll a fluorescence measurements of isolated spinach thylakoids obtained by using single-laserbased flow cytometry

Cytometry, 11 (1990), pp. 349-358

C.M. Yentsch, P.K. Horan

Cytometry in the aquatic sciences

Cytometry, 10 (1989), pp. 497-499

C.M. Yentsch, S.A. Pomponi

Automated individual cell analysis in aquatic research

Int Rev Cytol, 105 (1986), pp. 183-243

Corresponding author. Tel.: +34-981-167000; fax: +34-981-167065

Copyright (C) 2000 Elsevier Science B.V. All rights reserved. 